\title{
BMJ Open Description and preliminary results from a structured specialist behavioural weight management group intervention: Specialist Lifestyle Management (SLiM) programme
}

Adrian Brown, ${ }^{1,2}$ Amy Gouldstone, ${ }^{1}$ Emily Fox, ${ }^{1}$ Annmarie Field, ${ }^{1}$ Wendy Todd, ${ }^{1}$ Jayadave Shakher, ${ }^{1}$ Srikanth Bellary, ${ }^{1,3}$ Ming Ming Teh, ${ }^{1}$ Muhammad Azam, ${ }^{1}$ Reggie John, ${ }^{1}$ Alison Jagielski, ${ }^{4}$ Teresa Arora, ${ }^{5}$ G Neil Thomas, ${ }^{6,7}$ Shahrad Taheri ${ }^{1,4,5,8,9}$

To cite: Brown A, Gouldstone A, Fox E, et al. Description and preliminary results from a structured specialist behavioural weight management group intervention: Specialist Lifestyle Management (SLiM) programme. BMJ Open 2015:5:e007217. doi:10.1136/bmjopen-2014007217

- Prepublication history for this paper is available online. To view these files please visit the journal online (http://dx.doi.org/10.1136/ bmjopen-2014-007217).

Received 17 November 2014 Revised 26 December 2014 Accepted 29 December 2014

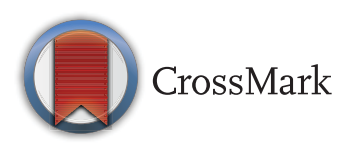

For numbered affiliations see end of article.

Correspondence to Professor Shahrad Taheri; staheri@me.com

\section{ABSTRACT}

Background: Specialist Lifestyle Management (SLiM) is a structured patient education and self-management group weight management programme. Each session is run monthly over a 6 -month period providing a less intensive long-term approach. The groups are patientcentred incorporating educational, motivational, behavioural and cognitive elements. The theoretical background, programme structure and preliminary results of SLiM are presented.

Subjects/methods: The study was a pragmatic service evaluation of obese patients with a body mass index (BMI) $\geq 35 \mathrm{~kg} / \mathrm{m}^{2}$ with comorbidity or $\geq 40 \mathrm{~kg} / \mathrm{m}^{2}$ without comorbidity referred to a specialist weight management service in the West Midlands, UK. 828 patients were enrolled within SLiM over a 48-month period. Trained facilitators delivered the programme. Preliminary anonymised data were analysed using the intention-to-treat principle. The primary outcome measure was weight loss at 3 and 6 months with comparisons between completers and non-completers performed. The last observation carried forward was used for missing data.

Results: Of the 828 enrolled within SLiM, 464 completed the programme $(56 \%)$. The mean baseline weight was $135 \mathrm{~kg}\left(\mathrm{BMl}=49.1 \mathrm{~kg} / \mathrm{m}^{2}\right)$ with $87.2 \%$ of patients having a $B M l \geq 40 \mathrm{~kg} / \mathrm{m}^{2}$ and $12.4 \%$ with $\mathrm{BMI} \geq 60 \mathrm{~kg} / \mathrm{m}^{2}$. The mean weight change of all patients enrolled was $-4.1 \mathrm{~kg}(95 \% \mathrm{Cl}-3.6$ to $-4.6 \mathrm{~kg}$, $\mathrm{p}=0.0001)$ at the end of SLiM, with completers $(\mathrm{n}=464)$ achieving $-5.5 \mathrm{~kg}(95 \% \mathrm{Cl}-4.2$ to $-6.2 \mathrm{~kg}$, $\mathrm{p}=0.0001$ ) and non-completers achieving $-2.3 \mathrm{~kg}$ $(p=0.0001)$. The majority $(78.6 \%)$ who attended the 6-month programme achieved weight loss with $32.3 \%$ achieving a $\geq 5 \%$ weight loss.

Conclusions: The SLiM programme is an effective group intervention for the management of severe and complex obesity.

\section{Strengths and limitations of this study}

- A large comprehensive service evaluation of a programme for patients with severe and complex obesity within the UK National Health Service setting.

- Reduced contact and simplicity producing clinically significant weight loss outcomes.

- No comparison group (non-randomised study).

- Only initial data reported, therefore lack of longterm data up to 12 months.

- Future evaluation needed for educational and self-management elements of the Specialist Lifestyle Management programme.

\section{INTRODUCTION}

Obesity is a major challenge for health services worldwide. In particular, the percentage of patients with extreme and complex obesity is increasing with greater recourse to bariatric surgery. ${ }^{1} \quad$ Clinical obesity management guidelines recommend a multidisciplinary approach that includes behavioural intervention. ${ }^{2}{ }^{3}$ While intense behavioural interventions have been delivered successfully by several clinical trials, ${ }^{4} 5$ these interventions have not translated into usual care due to a variety of reasons including lack of suitable expertise and insufficient resources. Instead, structured educational programmes have been developed to improve self-management of chronic disorders such as diabetes mellitus, employing a group approach to improve patient knowledge and aid disease management. ${ }^{67}$ 
In the UK, recent commissioning policy ${ }^{8}$ for referral to bariatric surgery services states that patients are required referral from a specialist medical obesity service. These services also cater for a proportion of patients with extreme and complex obesity who prefer a medical solution. The effectiveness of specialist medical obesity services is, however, unknown. In the face of limited resources and in response to greater demands for specialist weight management services in the West Midlands, UK, the Specialist Lifestyle Management (SLiM) programme was developed. The theoretical background, structure and preliminary results from the SLiM programme are presented here to inform future service development and implementation.

\section{METHODS}

\section{Background}

The regional specialist weight management service at the Heart of England National Health Service (NHS) Foundation Trust, Birmingham, received patients with extreme and complex obesity from primary care based on the following referral criteria: a body mass index (BMI) of $40 \mathrm{~kg} / \mathrm{m}^{2}$ or above, or a BMI of $35 \mathrm{~kg} / \mathrm{m}^{2}$ with a comorbidity, such as type 2 diabetes mellitus. ${ }^{2}$ Patients were referred to the service by their general practitioner or hospital doctor having often exhausted all other avenues for weight loss, including commercial, primary care and community interventions. Prior to implementation of the SLiM programme, patients were initially reviewed by a physician with specialist interest in obesity and a care plan was agreed which included the SLiM programme. Only a minority of patients $(<10 \%)$ with specialist requirements were referred for individual dietetic aftercare, for example, those with end-stage renal failure and preparation for renal transplant, previous bariatric surgery and liver disease, and those who wished to be seen individually, which allowed them to 'opt-out'. Within this model, physicians, dieticians and dietetic assistants carried out all further follow-up, usually between 3 and 6 months after the initial visit which included arrangement and follow-up of relevant investigations (eg, sleep studies to exclude obstructive sleep apnoea), medication adjustment and, if required, individual psychological support. Any adjustments to medications were carried out by physicians within the clinic in collaboration with primary care. Following their initial clinical assessment (supported by the use of the Hospital Anxiety and Depression Scale questionnaire), any patient identified clinically to have underlying psychiatric or psychological issues requiring mental health support was discussed by the multidisciplinary team and referred to local mental health services or a psychologist within the clinic, respectively.

Frequent follow-up is an important factor in the success of weight loss programmes and weight maintenance. ${ }^{9}$ A review of the clinic referral numbers, capacity of current clinical resources and waiting times for new and review appointments highlighted that frequent individual support by bariatric physicians and dieticians was not feasible. Thus, there was a need to reformat the service to effectively cater for greater patient volume. This resulted in the design and implementation of the SLiM programme based on available evidence and recommendations.

\section{Aims of SLiM}

The aims of SLiM were:

- To achieve at least a 5\% weight loss;

- To educate patients regarding obesity;

- To encourage self-management of obesity.

\section{General structure of SLiM}

Multicomponent interventions combining diet, physical activity and behavioural modification have been highlighted as essential for weight loss and goal achievement, ${ }^{2}$ with a comprehensive behavioural approach producing a $10.7 \mathrm{~kg}(11 \%)$ weight loss while significantly reducing attrition. ${ }^{10}$ The SLiM programme aims to empower patients to make lifestyle and behavioural changes while providing them with weight maintenance strategies. Within SLiM, key behavioural theories and techniques are used to encourage lifestyle change and help participants gain control of eating behaviour and enable weight maintenance. The use of groups in weight management has been incorporated into a range of commercial and non-commercial programmes. ${ }^{11} 12$ Evidence suggests that group interventions may produce better weight loss outcomes than individual therapy; ${ }^{10} 1314$ even in patients who initially indicated a preference for individual care. ${ }^{15}$ Thus, a group approach was adopted in SLiM. SLiM is a monthly programme running for 6 months and designed to be delivered by a trained facilitator.

To aid the cost-effectiveness of the SLiM programme, dietetic assistants were selected as ideal programme facilitators. A variety of training methods for facilitators were used including direct observation of senior dieticians delivering the sessions, joint sessions, and session observation with feedback and follow-up work to aid learning. In addition, a structured approach to session delivery was used to ensure programme fidelity, with core topics to be covered within each session and standardised presentations. Sessions are provided on a weekly rolling basis to allow patients to attend any missed session; this is a unique format as usual group programmes run for between 6 and 12 weeks. SLiM sessions lasted between 60 and $90 \mathrm{~min}$ and had between 2 and 10 patients within each session.

\section{Components of SLiM}

Table 1 describes the behavioural modification strategies utilised in SLiM. The key components, including their theoretical background and evidence, are described in detail below. Table 2 lists the contents of each SLiM session. 
Table 1 Behavioural modification strategies used within the SLiM programme

\section{Behavioural modification technique}

Self-monitoring

Goal setting

Stimulus control

Cognitive restructuring

Eating behaviour

Maintenance

All or nothing beliefs

Reward and support

Problem solving

Self-esteem

\section{Description of specific tools within techniques}

Food and mood diary used to record foods eaten, when, where, with whom and relation with mood

Used to identify triggers and help the patient become more conscious about their eating behaviour

Techniques to help control perceived hunger

SMART goals are explained and a game is used to help patients' understanding

Patients encouraged to make long-term goals within brainstorming session and then encouraged to make individualised goals each month with regard to diet and physical activity Realistic personalised weight loss goal targets set at $5 \%$, weight monitoring chart given Identification of external and internal triggers using an association game Use of distraction techniques to help patients avoid excessive eating Discussions about negative thoughts and beliefs can inhibit the use of behavioural change, eg, 'l've had one biscuit, so l've ruined my diet'

Patients encouraged to change negative, unhelpful thoughts to more useful, positive ones, eg, 'One biscuit is not the end of the world and I can go for a walk tomorrow to burn it off' Patients trained to use positive self-talk and diaries to help with the process Patients educated on healthy eating using the principles of the eatwell plate Stabilisation of eating-regular meals

Portion size control discussed

Patients taught to read and interpret food labels using resources and labelling game Patients taught the difference between a slip-up and a setback and to avoid using terms that can encourage relapse, eg, failure

Patients encouraged to avoid all or nothing beliefs and shown how these affect food intake and achieving goals, eg, avoid the use of 'always' or 'never' or 'have to'

Non-food-related rewards are actively encouraged to aid motivation and help patients to move away from seeing food this way

Support is discussed along with getting patients to ask for this from family, friends and colleagues

How to identify negative support and deal with it to make it positive

Patients given skills and techniques to help with problem solving

Patients taught to plan for high-risk situations that could cause emotional or maladaptive eating

Brief discussion on how to improve self-esteem and feel good about one's self

SLiM, Specialist Lifestyle Management; SMART, Specific, Measurable, Achievable, Relevant and Time-Bound.

\section{Goal setting}

Goal setting techniques have been extensively used to encourage adoption of healthy behaviours, ${ }^{15} 16$ while allowing participants to assess progress. In SLiM, participants are encouraged to set weight loss and personal goals and these are subsequently subdivided into monthly goals for stepwise progress. Goal setting is focused around the principles of SMART (Specific, Measurable, Achievable, Relevant and Time-Bound). This is achieved initially using a theoretical example and reinforced with a specific example from the group.

Setting a realistic weight loss between 0.5 and $1 \mathrm{~kg} /$ week is recommended, ${ }^{16}$ with overall weight loss targets based on a clinically significant weight loss of $5-10 \%$ from initial weight. $^{17} 18$ This is calculated and written down for each patient; however, this is often significantly less than patients' expectations. ${ }^{19}$ There is evidence to suggest that unrealistic weight loss goals could affect overall weight loss. $^{20}$ In contrast, Linde et $a l^{19}$ found that more 'unrealistic' weight loss expectations were associated with greater long-term weight loss success. A recent metaanalysis ${ }^{21}$ has shown that the evidence is not favourable for the setting of realistic goals to improve weight loss outcome, suggesting that setting realistic weight loss goals might not be beneficial. It has, however, been shown that counselling patients on goal setting does help set more realistic weight losses in line with clinical guidelines, ${ }^{22}$ with the patient's satisfaction of that weight loss possibly being more important than matching their 'dream' weight. ${ }^{23}$

The amount of weight loss selected by the individual participant in SLiM is typically not shared with the group and patients are weighed at the end of the SLiM session instead of the beginning. The timing of the 'weigh in' has been found to be important, as during the initial pilot sessions it was observed that patients' interactions and emotional state became overly negative if they gained or even maintained weight and were weighed at the start of the session. 
Table 2 Contents of each individual SLiM session

\begin{tabular}{|c|c|c|}
\hline Session & Topics & Homework \\
\hline Session 1 & $\begin{array}{l}\text { Get to know each other } \\
\text { Weight loss expectations } \\
\text { Goal setting (SMART) } \\
\text { Self-monitoring } \\
\text { Healthy eating } \\
\text { Daily living activity ideas }\end{array}$ & $\begin{array}{l}\text { Food and mood diary } \\
\text { Increase intake of water } \\
\text { SMART nutrition goal }\end{array}$ \\
\hline Session 2 & $\begin{array}{l}\text { Energy balance } \\
\text { Macronutrient calories } \\
\text { Regular meals } \\
\text { Menu planning } \\
\text { Healthy cooking methods }\end{array}$ & $\begin{array}{l}\text { Reduce portions by } 25 \% \\
\text { SMART physical activity goal } \\
\text { Making your meals more balanced }\end{array}$ \\
\hline Session 3 & $\begin{array}{l}\text { Behavioural modification } \\
\text { Eating behaviour } \\
\text { Conscious eating } \\
\text { Thoughts, feelings, behaviours }\end{array}$ & $\begin{array}{l}\text { Increase variety of fruit and vegetables } \\
\text { Trigger identification and use techniques to help } \\
\text { Change a negative thought to positive one }\end{array}$ \\
\hline Session 4 & $\begin{array}{l}\text { Portion control } \\
\text { Recommended serving sizes } \\
\text { Label reading }\end{array}$ & $\begin{array}{l}\text { Use low Glycaemic Index information } \\
\text { Complete virtual shopping tour sheet }\end{array}$ \\
\hline Session 5 & Virtual shopping trip & $\begin{array}{l}\text { Reflection on the past } 6 \text { months and skills learnt } \\
\text { to help achieve goals }\end{array}$ \\
\hline Session 6 & $\begin{array}{l}\text { Thanks to everyone } \\
\text { Slip-ups } \\
\text { High-risk situation, } \\
\text { Self-esteem } \\
\text { Support and reward } \\
\text { How to continue-maintenance }\end{array}$ & \\
\hline
\end{tabular}

\section{Self-monitoring}

The use of self-monitoring helps patients change their eating behaviours. Patients who monitor eating, activity and weight on a regular basis have significantly greater weight loss and maintenance. ${ }^{24}$ Throughout SLiM, patients are encouraged to maintain a daily diary of all food and drink consumed, when they consume it, where, with whom, their hunger throughout eating and finally their mood. Unlike some programmes which encourage patients to follow a daily calorie and even fat intake, ${ }^{5}{ }^{12}$ SLiM focuses more on the patient's eating patterns, identification of triggers and enabling them to be more conscious eaters. One key element is emphasising that the diary is only for personal use and the facilitator will not see it unless the patient wishes them to. This allows for more open, realistic diaries to minimise under-reporting, which is the main disadvantage of food diaries. ${ }^{25}$ Hunger is an important factor within weight control ${ }^{26}$ therefore, providing techniques to help control hunger, identify satiety and the sense of deprivation often highlighted during 'dieting' behaviour could potentially be associated with better outcomes. ${ }^{11}$ Therefore, the use of a hunger scale and helping patients identify a sense of satisfaction, while moving away from using external cues of fullness (ie, plate being empty), allows patients to reduce their portion sizes themselves, giving them a sense of autonomy over how much they eat.

\section{Eating behaviour}

A key message within SLiM is regular meal intake. This is encouraged as studies have suggested that individuals who eat breakfast weigh less than those who typically skip this meal, ${ }^{27}$ although the exact mechanisms are unclear. ${ }^{28}$ Development of a regular structured meal pattern is the first step in dealing with erratic eating. ${ }^{29}$ Unlike other programmes which give patients a prescribed eating plan of 500-600 calories deficit per day, ${ }^{5}{ }^{12}$ by calculating estimated resting metabolic rate (RMR) using predictive equations, patients are provided with behavioural techniques to reduce portions and identify internal triggers of satiation. Patients are also educated regarding portions and serving control, providing a less prescriptive approach. Furthermore, there is significant evidence to show that the use of predictive equations for RMR within the obese is unreliable ${ }^{30} 31$ and rarely valid within the obese population. ${ }^{32}$ This could provide hypercalorific or hypocalorific energy intakes, which may in part explain this technique's lack of long-term success in the treatment of obesity.

The nutritional recommendations within SLiM are initially based on guidance for healthy eating produced by the UK Department of Health, ${ }^{33}$ using the eatwell plate. These healthy diet principles are based on starchy foods (carbohydrate based), having five servings of fruit and vegetables daily, reducing the total fat intake within the diet, particularly from sources such as sweets, crisps and 
animal fats and replacing them with unsaturated sources, and having high-quality sources of protein and dairy foods. This information is discussed within a group environment to enable patients to gauge the discrepancy between their current intake and the recommendations.

Often, obese individuals' eating behaviour, characterised by maladaptive ${ }^{34}$ and uncontrolled eating, combined with dysfunctional or distorted body-related beliefs, ${ }^{35}$ affect their ability to lose weight. Strategies from cognitive therapy enable patients to begin to identify and modify dysfunctional thought patterns and consequences of negative mood states. Examining how magnifying negative thoughts about themselves or situations, or failing to identify positives, can affect their ability to make lifestyle changes. How to challenge and change these to be positive ${ }^{36}$ is an essential component. Other skills used to aid behavioural change are helping to identify the locus of control. Enabling a patient to understand their locus of control allows them to appreciate their responses, recognise their ability to change their lifestyle and achieve their goals. ${ }^{11}{ }^{37}$ Furthermore, the use of definitive words such as 'must', 'always', 'never' and 'can't' are highlighted to make the patient aware of negative words and how these might prevent success. These are then rephrased by using positive language such as 'I will aim to', 'I will aim not to' and 'I can' to help support change.

The ability to cope with life stresses and not turn towards food as a coping mechanism is an important factor to address. This has been defined as managing external and internal triggers that are seen as taxing or exceeding the resources of the person, by using cognitive and behavioural techniques and skills. ${ }^{38}$ Helping patients cope more easily with cravings and using coping techniques to help in relapse situations have been shown to help with weight loss and maintenance. ${ }^{39} 40$ Furthermore, problem-solving techniques are taught to allow effective coping with triggers and stresses. This uses multistep problem-solving techniques to help during stressful times. ${ }^{36}{ }^{41}$ These are supported by stimulus control principles, which enable patients to gain control and change their environment (eg, home and/ or workplace) to allow for successful behaviour and lifestyle change. By facilitating an environment that reduces exposure to high-calorie foods, this should reduce consumption of these foods. Also, SLiM encourages increasing exposure to healthy foods and snacks and promotes physical activity by, for example, having walking/running shoes by the front door.

\section{Weight loss maintenance}

Throughout the programme, weight loss maintenance skills are taught. This upskilling equips the patient to anticipate and cope with circumstances that could bring about lapses and relapses. ${ }^{42}$ Several skills are highlighted throughout SLiM to help with this process (table 1). Some of the key aspects include recognising and identifying situations that have the potential of high-relapse risk and develop problem-solving techniques to cope with them. ${ }^{43}$ Ongoing vigilance and eating and physical activity self-monitoring are pre-requisites to achieving weight loss maintenance. ${ }^{42} 44$

The US National Weight Control Registry ${ }^{45}$ highlights three main factors that play a distinct role within SLiM, with these factors being consistently emphasised to facilitate continuing behavioural change. These are: (A) eating a diet low in fat, (B) frequent self-monitoring and (C) regular physical activity. Additionally, social support and positive reinforcement are considered to be important for continued weight loss maintenance $;^{38}$ therefore, patients are encouraged to mobilise their support network including family and friends. ${ }^{46}$ There are suggestions, however, that interference from life partners could affect weight loss maintenance. ${ }^{38}$ To address this, SLiM highlights areas where this could occur and appropriate tactics are discussed. Finally, the importance of self-esteem is also addressed, as it has been suggested to be an important relapse trigger. ${ }^{47}$

\section{Physical activity}

Physical activity has a positive effect on weight loss maintenance and cardiovascular health. ${ }^{48}{ }^{49}$ For the majority of SLiM patients with extreme and complex obesity, physical activity is difficult due to issues of extreme obesity and conditions such as arthritis. SLiM primarily aims to encourage a reduction in sedentary behaviours,$^{50}$ although for those able to do physical activity, they are advised to follow recommendations for health by engaging in physical activity for at least $30 \mathrm{~min} /$ day, 5 days/week. ${ }^{2}{ }^{51}$ For individuals already achieving this, higher physical activity levels are encouraged for optimal weight loss and maintenance but also aim to ensure that patients keep within their maintainable limits and seek medical advice. ${ }^{52}$ Potential benefits of using a variety of physical activities are highlighted.

\section{Patient educational material and homework}

Patient educational materials are integral in SLiM to support and reinforce the topics covered. Diet sheets follow NHS guidelines including using an easy to read font and size. ${ }^{53}$ The materials have additional homework elements to consolidate the learning points from each session and prepare the patient for the next session's topics such as the supermarket tour. These also incorporate visual and written elements to aid learning and information retention.

\section{Patient feedback}

Over time, evaluation and patient feedback is key to help inform and improve clinical practice and has been used to help the SLiM programme to become more patient focused. Regular feedback was used to gain information about content, length of session, whether the sessions met expectations and areas where improvements could be made. 


\section{Statistical analysis}

Preliminary anonymised data from the SLiM programme were analysed using the intention-to-treat principle. The primary outcome measure examined was weight loss. Descriptive statistical methods were used to present change in weight at 3 and 6 months for all patients, completers and non-completers. Values are presented as means (SDs) or medians (IQR) for continuous variables and as frequencies (percentages) for categorical variables. Normally distributed data and skewed data were analysed using appropriate tests ( $\mathrm{t}$ tests, repeated measure analysis of variance, Mann-Whitney U test and Wilcoxon signed-rank test) to compare weight loss and BMI from referral to the end of SLiM and the differences between completers and noncompleters. Patients were considered to be completers of the SLiM programme if they had attended all six sessions within the SLiM programme, with total patients enrolled within the programme being defined as the patients who attended at least one session. Percentages between different categorical weight losses at the end of SLiM were compared using $\chi^{2}$ tests. We present weight change as absolute weight change, percentage weight change, median weight change, BMI change and also percentages achieving at different categorical weight losses. If there were missing data, the last observation carried forward (LOCF) was used. Statistical significance was be set at $p$ value $\leq 0.05$. All analyses were conducted with IBM SPSS Statistics V.20 (SPSS Inc, Chicago, Illinois, USA).

\section{RESULTS}

Of 828 patients enrolled within the SLiM programme, 464 completed the programme between August 2009 and June 2013. The characteristics are shown in table 3 comparing completers and non-completers. The majority of the patients were women $(73.7 \%)$, representing a similar distribution to other studies. ${ }^{55} 56$ The mean age was 48.2 years, and $80 \%$ were white European. The mean weight on referral was $135 \mathrm{~kg}$ with a mean BMI of $49.1 \mathrm{~kg} / \mathrm{m}^{2}$. Diabetes was present in $32.1 \%$ of patients. The session attendance for non-completers showed that the majority $(57.7 \%)$ only attended the first two sessions (36 and 21.7 for sessions 1 and 2 respectively). Non-attendance then reduced to between $12 \%$ and $17 \%$ for the subsequent sessions, with all 364 non-completers attending between one and five sessions.

By comparing the completers and non-completers, it was found that the completers were significantly older ( 49.2 compared with 46.9 years, $\mathrm{p}=0.005$ ), had a greater prevalence of obstructive sleep apnoea $(\mathrm{p}=0.0001)$ and had a greater referral BMI $(\mathrm{p}=0.02)$. There were no significant differences in the other measures (table 3). Table 3 shows that SLiM produced a significant difference between referral weight and BMI and the end of SLiM within all subgroups.

The change in body weight for all the patients enrolled in SLiM ranged from $58.4 \mathrm{~kg}$ loss to a gain of $14.8 \mathrm{~kg}$, with a mean BMI change of $-1.48 \mathrm{~kg} / \mathrm{m}^{2}(95 \%$

Table 3 Characteristics for all patients, completers and non-completers in the SLiM programme

\begin{tabular}{|c|c|c|c|c|}
\hline Characteristics & Total & Completers & Non-completers & p Value \\
\hline Patients enrolled, n (\%) & 828 & $464(56)$ & $364(44)$ & \\
\hline Age in years (SD) & $48.2 \pm 11.6$ & $49.2 \pm 11.5$ & $46.9 \pm 11.6$ & 0.005 \\
\hline Sex, n (\%) & & & & 0.4 \\
\hline Men & $218(26.3)$ & $127(27.4)$ & $91(25)$ & \\
\hline Women & $610(73.7)$ & $337(72.6)$ & $273(75)$ & \\
\hline Ethnicity, n (\%) & & & & 0.06 \\
\hline White & $662(80)$ & $375(80.8)$ & $287(78.8)$ & \\
\hline Mixed & $6(0.7)$ & $3(0.6)$ & $3(0.8)$ & \\
\hline Asian & $94(11.4)$ & $44(9.5)$ & $50(13.7)$ & \\
\hline Black & $55(6.6)$ & $38(9.2)$ & $17(4.7)$ & \\
\hline Other & $11(1.3)$ & $4(0.8)$ & $7(1.9)$ & \\
\hline Mental health disorders, n (\%) & $216(26.1)$ & $117(25.2)$ & $99(27.2)$ & 0.5 \\
\hline Obstructive sleep apnoea, n (\%) & $332(40.1)$ & $218(47)$ & $114(31.3)$ & 0.0001 \\
\hline Diabetes, $\mathrm{n}(\%)$ & $266(32.1)$ & $157(33.8)$ & 109 (29.9) & 0.2 \\
\hline Insulin, $\mathrm{n}(\%)^{*}$ & $62(23.3)$ & $31(19.7)$ & $31(28.4)$ & 0.3 \\
\hline Oral hypoglycaemics, $n(\%)^{\star} \dagger$ & $214(80.5)$ & $130(82.8)$ & $84(77.1)$ & 0.1 \\
\hline Incretin based, $n(\%)^{*} \ddagger$ & $104(39)$ & $59(37.6)$ & $45(41.3)$ & 0.9 \\
\hline \multicolumn{5}{|l|}{ Obesity measures } \\
\hline Baseline weight kg (SD) & $135 \pm 28.1$ & $137.2 \pm 28.2$ & $133.6 \pm 28$ & 0.07 \\
\hline Baseline BMI kg/m², mean (SD) & $49.1 \pm 9.2$ & $49.8 \pm 9.3$ & $48.2 \pm 9.1$ & 0.02 \\
\hline Final weight $\mathrm{kg}(\mathrm{SD})$ & 131.4 & 131.6 & 131.2 & $0.0001 \S$ \\
\hline Final BMI $\mathrm{kg} / \mathrm{m}^{2}$, mean (SD) & 47.6 & 47.7 & 47.4 & $0.0001 \S$ \\
\hline \multicolumn{5}{|c|}{$\begin{array}{l}\text { p Values were calculated using either the independent } t \text { test or } \chi^{2} \text { test, as appropriate, comparing } \\
\text { *Values as a percentage of the participants with diabetes within each group. } \\
\text { †Oral hypoglycaemics=metformin and gliclazide combined. } \\
\text { †lncretin-based=GLP-1 analogues and gliptins combined. } \\
\text { §Comparisons between baseline and final weight and BMI for each subgroup. } \\
\text { BMI, body mass index; GLP-1, glucagon-like peptide-1; SLiM, Specialist Lifestyle Management. }\end{array}$} \\
\hline
\end{tabular}


Table 4 Weight loss and BMI of completers and non-completers enrolled to the SLiM programme

\begin{tabular}{|c|c|c|c|c|c|c|c|}
\hline $\begin{array}{l}\text { Follow-up } \\
\text { attendance } \\
\text { (months) }\end{array}$ & $\begin{array}{l}\text { Total } \\
\text { (n) }\end{array}$ & $\begin{array}{l}\text { Mean weight } \\
\text { loss, kg (SD) }\end{array}$ & Median (IQR) & p Value & $\begin{array}{l}\text { Mean BMI } \\
\text { loss, kg/m² (SD) }\end{array}$ & Median (IQR) & p Value \\
\hline \multicolumn{8}{|l|}{ Completers } \\
\hline 0 & & - & - & & - & - & \\
\hline 3 & 404 & $-3.7(5.4)$ & $-2.6(-0.4-6.0)$ & 0.0001 & $-1.3(2.1)$ & $-1.0(-0.1-2.2)$ & 0.0001 \\
\hline 6 & 464 & $-5.5(7.4)$ & $-4.1(-1.0-8.6)$ & 0.0001 & $-2.0(2.8)$ & $-1.6(-0.4-2.9)$ & 0.0001 \\
\hline \multicolumn{8}{|c|}{ Non-completers } \\
\hline 0 & & - & - & & - & - & \\
\hline 3 & 143 & $-3.2(5.7)$ & $-2.0(-0.4-5.4)$ & 0.0001 & $-1.1(2.1)$ & $-0.8(-0.1-1.9)$ & 0.0001 \\
\hline 6 & 364 & $-2.3(6.8)$ & $-1.0(-0.9-4.3)$ & 0.0001 & $-0.8(2.4)$ & $-0.4(-0.3-1.6)$ & 0.0001 \\
\hline \multicolumn{8}{|c|}{ Subset diabetics } \\
\hline 6 & 142 & $-5.7(6.9)$ & $-4.7(-1.9-8.3)$ & 0.0001 & $-1.2(8.9)$ & $-1.6(-0.7-2.8)$ & 0.09 \\
\hline \multicolumn{8}{|c|}{$\begin{array}{l}\text { Weight loss and BMI values were calculated according to a median split. } \\
\text { Data are presented as mean (SD), median (IQR). } \\
\text { p Values were calculated using either the independent t test or related sample Wilcoxon signed-rank test, as appropriate, compared with } \\
\text { referral weight and BMI within separate subgroups. } \\
\text { Completers attended all six sessions with the LOCF used for missing data for non-completers. } \\
\text { BMI, body mass index; LOCF, last observation carried forward; SLiM, Specialist Lifestyle Management. }\end{array}$} \\
\hline
\end{tabular}

CI -1.3 to $-1.7 \mathrm{~kg} / \mathrm{m}^{2}$ ) and a mean weight loss of -4.1 $\pm 7.3 \mathrm{~kg}(95 \%$ CI -3.1 to $-4.0 \mathrm{~kg}, \mathrm{p}=0.0001)$, equal to 2.9 $\pm 4.9 \%$ weight loss at the end of SLiM (table 4 ). Of the patients started SLiM, 68.4\% lost weight while $20.9 \%$ gained weight. The percentage achieving $\geq 5 \%$ weight loss was $24.9 \%$ at the end of SLiM, with $7.7 \%$ of patients achieving $\geq 10 \%$ weight loss (figure 1 ).

Table 3 summarises the weight loss achieved by the completers and non-completers over the SLiM programme. Of the patients who completed the SLiM programme, the mean weight loss was $-5.5 \mathrm{~kg}(95 \% \mathrm{CI}$ -4.9 to $-6.2 \mathrm{~kg}, \mathrm{p}=0.0001$ ), with a mean BMI change of $2.0 \mathrm{~kg} / \mathrm{m}^{2}\left(95 \% \mathrm{CI}-1.7\right.$ to $\left.-2.2 \mathrm{~kg} / \mathrm{m}^{2}, \mathrm{p}=0.0001\right)$, with a percentage weight loss of $3.9 \pm 5 \%$ and $32.3 \%$ achieving a $\geq 5 \%$ weight loss compared with $15.4 \%$ of noncompleters. By comparing this with the non-completers, it was found that there was a clinically and statistically significant difference in weight loss and percentage weight loss achieved (5.5 kg vs $2.3 \mathrm{~kg}$, and $3.9 \%$ vs $1.7 \%$ respectively, both $\mathrm{p}=0.0001)$. A significantly greater percentage of completers compared with non-completers achieved weight loss at all the weight loss categories $(p=0.05$; figure 1$)$. Significantly more non-completers than completers $(28.3 \%$ vs $15.1 \%)$ gained weight from referral to completion of SLiM ( $p=0.0001)$.

Data from a subset analysis of 142 patients with diabetes who completed the SLiM programme showed that the mean age of patients with diabetes was slightly greater at $52.5 \pm 11$ years, and a smaller percentage were women $(64.8 \%)$, with a comparable BMI and weight of $50 \mathrm{~kg} / \mathrm{m}^{2}$ and $137 \mathrm{~kg}$, respectively, compared with patients without diabetes. At baseline, the mean glycated hemoglobin (HbAlc) was $64 \pm 18.2 \mathrm{mmol} / \mathrm{mol}(8 \pm 3.8 \%)$. At the end of SLiM, there was a clinically and statistically significant reduction in mean $\mathrm{HbAlc}$ levels from baseline, with the mean $\mathrm{HbAlc}$ falling to $60.1 \pm 15.5 \mathrm{mmol} / \mathrm{mol}(7.6 \pm 3.6 \%)$,
Figure 1 Percentage of participants for all patients, completers and non-completers achieving different categorical weight loss (eg, maintainer, $<5 \%$, $\geq 10 \%$, etc). The weight losses are cumulative. Weight gainers are participants gaining $\geq 0.5 \%$ in weight. " $p$ Values $<0.05$ comparing weight loss between completers and non-completers at individual categorical weight loss groups.

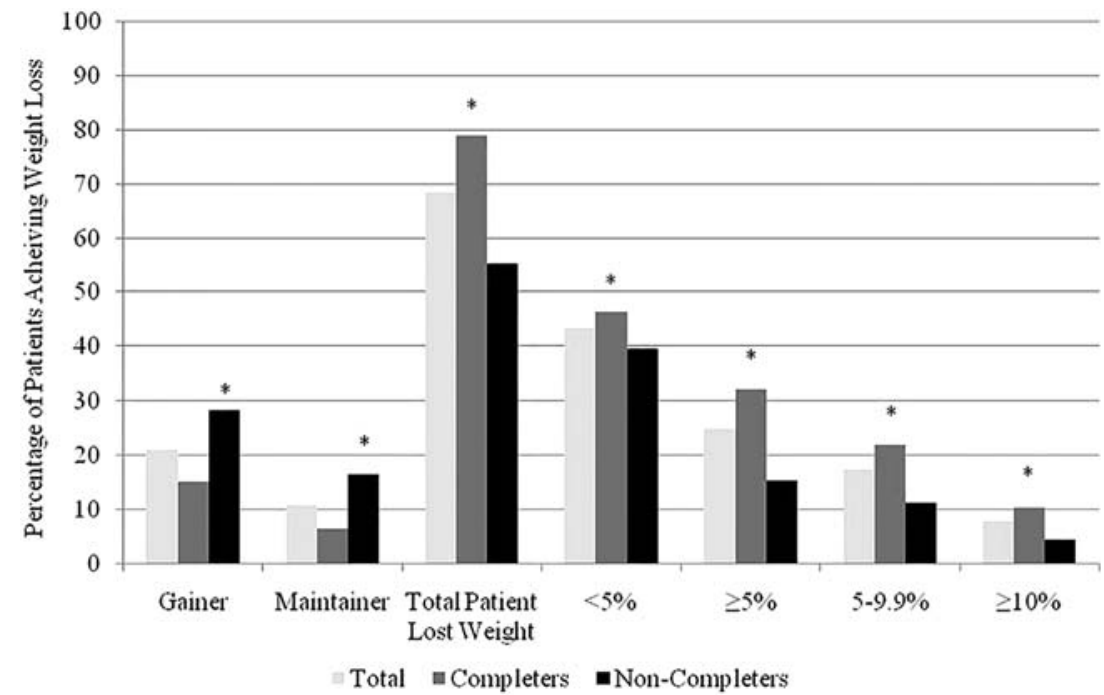


a mean reduction of $3.96 \pm 14.8 \mathrm{mmol} / \mathrm{mol} \quad(\mathrm{p}<0.05)$. Patients lost a clinically and statistically significant mean body weight ranging from a $29.8 \mathrm{~kg}$ loss to a gain of $8.8 \mathrm{~kg}$. The mean weight loss was $5.71 \pm 6.89 \mathrm{~kg}(\mathrm{p}=0.001)$, which was similar to that of the overall population, with $30 \%$ of patients achieving $\geq 5 \%$ and $11 \%$ achieving a $\geq 10 \%$ weight loss with a mean weight loss of $4 \pm 4.57 \%$ being achieved in the weight loss group $(\mathrm{p}=0.0001)$.

\section{DISCUSSION}

The SLiM programme is an innovative group intervention to help treat obese patients within a specialist weight management service. From the results presented, using the SLiM model has helped patients achieve a clinically significant weight loss and improvement in diabetes control. The programme is unique as it provides care to patients within a specialist service while giving support over a 24-week period instead of the typical 6-12 week programmes commonly implemented. ${ }^{753}$

The weight and BMI reduction observed with SLiM are comparable to those within more intensive weight loss trials, in addition to commercial and primary care lifestyle interventions. ${ }^{4} 511$ 54-56 For example, the Counterweight programme achieved a $4.24 \mathrm{~kg}$ weight loss and a BMI reduction of $1.55 \mathrm{~kg} / \mathrm{m}^{2}$ for the attendees compared with the $5.5 \mathrm{~kg}$ weight loss and a reduction of $2 \mathrm{~kg} / \mathrm{m}^{2}$ for more complex cases within the SLiM programme.

With much of the current literature being based within a primary care or commercial group settings, ${ }^{53} 54$ direct comparison of SLiM with other programmes is difficult given the greater burden and complexity of obesity for SLiM participants. The most similar service evaluation to that of the present study is that of the Glasgow and Clyde Weight Management Service (GCWMS). ${ }^{55} 56$ The phase 1 group programme comprised of nine fortnightly sessions of diet, exercise and behavioural intervention over a 16 -week period is the first of three phases. The mean weight loss for all patients (LOCF) attending these phase 1 groups at the end of the 16 weeks was $-3.06 \mathrm{~kg}$ compared with a similar $4.1 \mathrm{~kg}$ for all SLiM patients. $36 \%$ of phase $1 \mathrm{com}-$ pleters ( $\mathrm{n}=1322)$ lost $\geq 5 \mathrm{~kg}$ compared to $44.4 \%$ of SLiM completers $(\mathrm{n}=464)$. When comparing identical timepoint data at 6 months (including phases 1 and 2), the results were again very similar with $50 \%$ losing $\geq 5 \mathrm{~kg}$. ${ }^{56}$ Although similar results were achieved within both specialist services, the SLiM programme had significantly reduced clinical contact and was facilitated by a dietetic assistant, which could be more cost-effective.

Of the patients who completed SLiM, 32.3\% achieved a clinically significant weight loss $\geq 5 \%$ initial body weight, which again is comparable to other UK-based lifestyle interventions. ${ }^{4545758}$ Importantly, $78.6 \%$ of the patients who completed the SLiM programme lost weight with an additional $6.3 \%$ maintaining their weight, giving a total of $84.9 \%$ who lost or maintained their weight during the study period.
A recent randomised control Lighten Up trial ${ }^{53}$ examined the effectiveness of local non-specialist weight management services within the West Midlands. They compared the three main commercial weight loss programmes with local healthcare professional options including dietetic-led or pharmacy-led programmes and general practice one-to-one counselling. The study reported statistically significant weight loss for all programmes ranging from 1.37 to $4.43 \mathrm{~kg}(\mathrm{p}=0.001)$ at 12 weeks. However, patients attending the commercial group session, Weight Watchers, Slimming World and Rosemary Connelly, lost on average $2.3 \mathrm{~kg}$ (95\% CI 1.3 to 3.4, $\mathrm{p}=0.004$ ) more than the primary care programmes. The percentage of patients achieving $5 \%$ weight loss or more ranged from $16 \%$ to $46 \%$, with Weight Watchers (46\%) and Rosemary Conley (42\%) performing the best. One aspect of this high percentage could have been related to the lower referral weights and the relative weight loss to achieve this target. A key part of these commercial groups in helping patients lose weight has been suggested to be the peer support, supporting patterns of behaviour, preventing relapse and promoting weight maintenance. ${ }^{11}$ As these elements are also incorporated in SLiM, this might be an explanation in part to the success of SLiM, which enables reinforcement of essential messages and possibly encourages changing behaviour.

The SLiM programme produced a significant weight loss and improvement in glycaemic control in patients with diabetes. Over the initial 4-month period, the diabetes education programme, X-Pert, ${ }^{7}$ showed a mean reduction of HbAlc of $0.4 \%$ (CI $0.1 \%$ to $0.7 \%$ ), which is similar to the mean reduction found in SLiM. Even small reductions of HbAlc have been shown to have significant reductions in diabetes complications. ${ }^{59}$ However, one significant difference between SLiM and X-Pert was the amount of weight lost over the period of the programmes, with the subset of diabetic SLiM completers achieving a $5.5 \mathrm{~kg}$ weight loss compared to $0.3 \mathrm{~kg}$ within the X-Pert group. Focusing on weight loss and not glycaemic control might be an important way of improving diabetes complications while producing clinically significant weight loss, although more controlled investigations are needed to confirm these findings.

Consistent with other interventions, ${ }^{54}$ the most favourable results were seen in the completers compared with the non-completers, suggesting that patient cooperation, optimisation of attendance and retention of patients are important aspects for improved weight loss outcome. In the present evaluation, $56 \%$ of participants who started SLiM programme completed all the sessions. Pragmatic solutions to reduce non-completion included did not attend letters and reinforcing attendance within physician follow-up. With high dropout rates often being found within obesity treatments, further investigation is warranted to aid greater understanding of predictors and reasons for attrition.

The strengths of this study are that this is one of the first evaluations of an effective specialist service for 
complex and severe obesity within the UK NHS setting including a large number of patients in a UK region with significant levels of obesity. The programme was developed based on current available evidence and extensive clinical experience. The evaluation also examined the impact on diabetes, a common and devastating comorbidity. There are a number of limitations to this study. This study was a non-randomised pragmatic service evaluation. In addition, long-term data are not available at this time, which would have been useful to demonstrate maintenance of weight loss following the initial 6 months. In addition, a more formal evaluation of the programme's aim regarding education and patient selfmanagement is required. Further evidence is required from a randomised control study to assess the short-term and long-term clinical and cost-effectiveness of SLiM programme. Another consideration is that a significant proportion of patients did not attend all the sessions, although the majority of non-completers attended the first two sessions. Future work should explore and identify the complex patient and intervention-related factors that determine programme completion.

\section{CONCLUSION}

In conclusion, we have shown that SLiM can achieve a clinically significant weight loss, which is comparable to more intensive programmes. However, there is a need for further long-term data analysis and assessment of predictors of attrition to allow this study to have greater generalisability. With the dearth of research into the treatment of severe and complex obesity within the specialist weight management service within the UK, the SLiM programme provides an innovative, practical model to help cater for the increasing number of patients with extreme obesity who require specialist obesity management.

\section{Author affiliations}

${ }^{1}$ Specialist Weight Management Services, Heart of England NHS Foundation Trust, Birmingham, UK

${ }^{2}$ Department of Diabetes, Endocrinology and Metabolism, Faculty of Medicine, Imperial College, London, UK

${ }^{3}$ School of Life and Health Sciences, Aston University, Birmingham, UK

${ }^{4}$ Theme 8 (Diabetes), Birmingham and Black Country NIHR CLAHRC, University of Birmingham, Birmingham, UK

${ }^{5}$ Department of Medicine, Weill Cornell Medical College, Doha, Qatar

${ }^{6}$ Public Health, Epidemiology and Biostatistics, University of Birmingham, Birmingham, UK

${ }^{7}$ Mannheim Medical Faculty, Institute of Public Health, Social and Preventive Medicine, Heidelberg University, Mannheim, Germany

${ }^{8}$ Department of Medicine, Kings College London, London, UK

${ }^{9}$ Department of Diabetes and Specialist Weight Management Service, Hamad Medical Corporation, Doha, Qatar

Acknowledgements The authors would like to acknowledge the patients and clinic staff of the specialist weight management service.

Contributors $A B$ developed the concept of SLiM with support from ST. AB was the lead dietician and ST the lead physician within the specialist service supporting SLiM. AB with the help of AF and WT wrote the content of the sessions. ST, JS, SB, MA and RJ were physicians within the specialist service. $A G$ provided dietetic support to SLiM. $A B, A G$ and $A J$ contributed to data collection and preparation. $A B, S T$ and GNT developed the service evaluation and data analysis plan. $A B$ carried out the data analysis with support from TA. AB wrote the first draft. AB, GNT and ST prepared subsequent drafts. All authors reviewed the final draft prior to submission.

Funding Professor Shahrad Taheri and Dr Teresa Arora are funded by the Biomedical Research Program at Weill Cornell Medical College supported by Qatar Foundation.

Competing interests None.

Provenance and peer review Not commissioned; externally peer reviewed.

Data sharing statement Extra data can be accessed via the Dryad data repository at http://datadryad.org/ with the doi:10.5061/dryad.g2q42.

Open Access This is an Open Access article distributed in accordance with the Creative Commons Attribution Non Commercial (CC BY-NC 4.0) license, which permits others to distribute, remix, adapt, build upon this work noncommercially, and license their derivative works on different terms, provided the original work is properly cited and the use is non-commercial. See: http:// creativecommons.org/licenses/by-nc/4.0/

\section{REFERENCES}

1. Leong WB, Taheri S. The role of bariatric surgery in the treatment of type 2 diabetes mellitus. J R Coll Physicians Edinb 2012;42:194-8.

2. National Institute for Health and Clinical Excellence Obesity. Guidance on the prevention, identification, assessment and management of overweight and obesity in adults and children: NICE clinical guideline 43. 2006. http://www.nice.org.uk/pdf/scope_obesity. pdf (accessed 5 Jun 2013).

3. Berkel LA, Poston CWS, Reeves RS, et al. Behavioural Interventions for Obesity. J Am Diet Assoc 2005;105(5 Suppl 1):S35-43.

4. Diabetes Prevention Programme Research Group. Reduction in the incidence of type 2 diabetes with lifestyle intervention or metformin. N Engl J Med 2002;346:393-403.

5. The Look AHEAD Research Group. Look AHEAD (Action for Health in Diabetes): design and methods for a clinical trial of weight loss for the prevention of cardiovascular disease in type 2 diabetes. Control Clin Trials 2003;24:610-28.

6. DAFNE Study Group. Training in flexible, intensive insulin management to enable dietary freedom in people with type 1 diabetes: dose adjustment for normal eating (DAFNE) randomised controlled trial. BMJ 2002;325:1-6.

7. Deakin TA, Cade JE, Williams R, et al. Structured patient education: the diabetes X-PERT Programme makes a difference. Diabet Med 2006;23:944-54.

8. Clinical Commissioning Policy: Complex and Specialised Obesity Surgery. April 2013. http://www.england.nhs.uk/wp-content/uploads/ 2013/04/a05-p-a.pdf (accessed 20 Nov 2013).

9. Wadden TA, Neiberg RH, Wing RR, et al. Four-year weight losses in the Look AHEAD study: factors associated with long-term success. Obesity (Silver Spring) 2011;19:1987-98.

10. Wadden TA, Butryn ML, Wilson C. Lifestyle modification for the management of obesity. Gastroenterology 2007;132:2226-38.

11. Stubbs J, Brogelli D, Pallister C, et al. Behavioural and motivational factors associated with weight loss and maintenance in a commercial weight management programme. Open Obes $J$ 2012;4:35-43.

12. Counterweight Project Team. A new evidence-based model for weight management in primary care: the Counterweight Programme. J Hum Nutr Diet 2004;17:191-208.

13. Ayyad C, Andersen T. Long-term efficacy of dietary treatment of obesity: a systematic review of studies published between 1931 and 1999. Obes Rev 2000;1:113-19.

14. Renjilian DA, Perri MG, Nezu AM, et al. Individual versus group therapy for obesity: effects of matching participants to their treatment preferences. J Consult Clin Psychol 2001;69:717-21.

15. Cullen KW, Baranowski T, Smith SP. Using goal setting as a strategy for dietary behaviour change. J Am Diet Assoc 2001;101:562-6.

16. Butryn ML, Webb V, Wadden TA. Behavioral treatment of obesity. Psychiatr Clin North Am 2011;34:841-59.

17. Avenell A, Broom J, Brown TJ, et al. Systematic review of the long-term effects and economic consequences of treatments for obesity and implications for health improvement. Health Technol Assess 2004;8:1-182. 
18. Scottish Intercollegiate Guidelines Network Management of Obesity: Guideline 115. 2010. http://www.sign.ac.uk/pdf/sign115.pdf (accessed 5 Jun 2013).

19. Linde JA, Jeffery RW, Finch EA et al. Are unrealistic weight loss goals associated with outcomes for overweight women? Obes Res 2004;12:569-76.

20. Teixeira PJ, Going SB, Houtkooper LB, et al. Pretreatment predictors of attrition and successful weight management in women. Int $J$ Obes Relat Metab Disord 2004;28:1124-33.

21. Durant $\mathrm{NH}$, Joseph RP, Affuso $\mathrm{OH}$, et al. Empirical evidence does not support an association between less ambitious pre-treatment goals and better treatment outcomes: a meta-analysis. Obes Rev 2013:14:532-40.

22. Finch EA, Linde JA, Jeffery RW, et al. The effects of outcome expectations and satisfaction on weight loss and maintenance: correlational and experimental analyses-a randomized trial. Health Psychol 2005:24:608-16.

23. Ohsiek S, Williams M. Psychological factors influencing weight loss maintenance: an integrative literature review. J Am Acad Nurse Pract 2011;23:592-601.

24. Wing RR, Hill JO. Successful weight loss maintenance. Annu Rev Nutr 2001;21:323-41.

25. Poslusna K, Ruprich J, de Vries $\mathrm{JH}$, et al. Misreporting of energy and micronutrient intake estimated by food records and 24 hour recalls, control and adjustment methods in practice. $\mathrm{Br} J$ Nutr 2009;101:S73-85.

26. Wing RR, Papandonatos G, Fava JL, et al. Maintaining large weight losses: the role of behavioral and psychological factors. J Consult Clin Psychol 2008;76:1015-21.

27. Wyatt HR, Grunwald GK, Mosca CL, et al. Long-term weight loss and breakfast in subjects in the National Weight Control Registry. Obes Res 2002;10:78-82.

28. Phelan S, Wyatt HR, Hill JO, et al. Are the eating and exercise habits of successful weight losers changing? Obesity (Silver Spring) 2006;14:710-16

29. Grace C. A review of one-to-one dietetic obesity management in adults. J Hum Nutr Diet 2011;24:13-22.

30. O'Riordan CF, Metcalf BS, Perkins JM, et al. Reliability of energy expenditure prediction equations in the weight management clinic. $J$ Hum Nutr Diet 2010;23:169-75.

31. Wilms B, Schmid SM, Ernst B, et al. Poor prediction of resting energy expenditure in obese women by established equations. Metabolism 2010;59:1181-9.

32. Frankenfield D, Roth-Yousey L, Compher C. Comparison of predictive equations for resting metabolic rate in healthy nonobese and obese adults: a systematic review. J Am Diet Assoc 2005;105:775-89.

33. Department of Health. About the eatwell plate. 2012. http://www.dh. gov.uk (accessed 9 Jun 2013).

34. Anderson K, Rieger E, Caterson I. A comparison of maladaptive schemata in treatment-seeking obese adults and normal-weight control subjects. J Psychosom Res 2006;60:245-52.

35. Werrij MQ, Jansen A, Mulkens S, et al. Adding cognitive therapy to dietetic treatment is associated with less relapse in obesity. J Psychosom Res 2009;67:315-24.

36. Van Dorsten B, Lindley EM. Cognitive and behavioral approaches in the treatment of obesity. Med Clin North Am 2011;95:971-88.

37. Nir Z, Neumann L. Relationship among self-esteem, internal external locus of control, and weight change after participation in a weight reduction program. J Clin Psychol 1995;51:482-90.

38. Elfhag K, Rössner S. Who succeeds in maintaining weight loss? A conceptual review of factors associated with weight loss maintenance and weight regain. Obes Rev 2005;6:67-85.

39. Dohm FA, Beattie JA, Aibel $\mathrm{C}$, et al. Factors differentiating women and men who successfully maintain weight loss from women and men who do not. J Clin Psychol 2001;57:105-17.
40. Ferguson KJ, Brink PJ, Wood M, et al. Characteristics of successful dieters as measured by guided interview responses and Restraint Scale scores. J Am Diet Assoc 1992;92:1119-21.

41. Gormally J, Rardin D. Weight loss and maintenance and changes in diet and exercise for behavioral counseling and nutrition education. J Couns Psychol 1981;28:295-304.

42. Brownell KD, Marlatt GA, Lichtenstein E, et al. Understanding and preventing relapse. Am Psychol 1986;41:765-82.

43. Perri MG, Sears SF Jr, Clark JE. Strategies for improving maintenance of weight loss. Toward a continuous care model of obesity management. Diabetes Care 1993;16:200-9.

44. Phelan S, Hill JO, Lang W, et al. Recovery from relapse among successful weight maintainers. Am J Clin Nutr 2003;78:1079-84.

45. Hill JO, Wyatt H, Phelan S, et al. The National Weight Control Registry: is it useful in helping deal with our obesity epidemic? J Nutr Educ Behav 2005;37:206-10.

46. Wing RR, Jeffery RW. Benefits of recruiting participants with friends and increasing social support for weight loss and maintenance. $J$ Consult Clin Psychol 1999;67:132-8.

47. Turner LW, Wang MQ, Westerfield RC. Preventing relapse in weight control: a discussion of cognitive and behavioral strategies. Psychol Rep 1995;77:651-6.

48. Church TS, Cheng YJ, Earnest CP, et al. Exercise capacity and body composition as predictors of mortality among men with diabetes. Diabetes Care 2004;27:83-8.

49. Wei M, Gibbons LW, Kampert JB, et al. Low cardiorespiratory fitness and physical inactivity as predictors of mortality in men with type 2. Diabetes Ann Intern Med 2000;132:605-11.

50. O'Donovan G, Blazevich AJ, Boreham C, et al. The ABC of physical activity for health: a consensus statement from the British Association of Sport and Exercise Sciences. J Sports Sci 2010;28:573-91.

51. Jeffery RW, Wing RR, Sherwood NE, et al. Physical activity and weight loss: does prescribing higher physical activity goals improve outcome? Am J Clin Nutr 2003;78:684-9.

52. Institute for Innovation and Improvement Patient Information. 2008. http://www.institute.nhs.uk/quality_and_service improvement tools/ quality_and_service_improvement_tools/patient_information.html (accessed 20 Nov 2013).

53. Jolly $\mathrm{K}$, Lewis $\mathrm{A}$, Beach $\mathrm{J}$, et al. Comparison of range of commercial or primary care led weight reduction programmes with minimal intervention control for weight loss in obesity: lighten up randomised controlled trial. BMJ 2011;3:343.

54. Counterweight Project Team. Evaluation of the Counterweight Programme for obesity management in primary care: a starting point for continuous improvement. Br J Gen Pract 2008;58:548-54.

55. Morrison DS, Boyle S, Morrison C, et al. Evaluation of the first phase of a specialist weight management programme in the UK National Health Service: prospective cohort study. Public Health Nutr 2012;15:28-38.

56. Logue J, Allardice G, Gillies M, et al. Outcomes of a specialist weight management programme in the UK National Health Service: prospective study of 1838 patients. BMJ Open 2014;4 e003747.

57. Ahern AL, Olson AD, Aston LM, et al. Weight Watchers on prescription: an observational study of weight change among adults referred to Weight Watchers by the NHS. BMC Public Health 2011:11:434.

58. Dixon KJ, Shcherba S, Kipping RR. Weight loss from three commercial providers of NHS primary care slimming on referral in North Somerset: service evaluation. J Public Health (Oxf) 2012;34:555-61.

59. Stratton IM, Adler AI, Neil HA, et al. Association of glycaemia with macrovascular and microvascular complications of type 2 diabetes (UKPDS 35): prospective observational study. BMJ 2000;321:405-12. 